\title{
E-Beam Processing of Collagen-Poly( $N$-vinyl-2-pyrrolidone) Double-Network Superabsorbent Hydrogels: Structural and Rheological Investigations
}

\author{
Maria Demeter ${ }^{1,2}$ \\ Ion Călina ${ }^{1,3}$ \\ Cătălin Vancea ${ }^{1,3}$ \\ Murat Şen ${ }^{4,5}$ \\ Mădălina Georgiana Albu Kaya ${ }^{6}$ \\ Elena Mănăilă ${ }^{1}$ \\ Marius Dumitru ${ }^{1}$ \\ Viorica Meltzer*,2 \\ ${ }^{1}$ National Institute for Lasers Plasma and Radiation Physics (INFLPR), 409 Atomiştilor, 077125, \\ Măgurele, Romania \\ ${ }^{2}$ University of Bucharest, Faculty of Chemistry, 4-12 Regina Elisabeta, 030018, Bucharest, Romania \\ ${ }^{3}$ University of Bucharest, Faculty of Physics, 405 Atomiștilor, 077125, Măgurele, Romania \\ ${ }^{4}$ Hacettepe University, Department of Chemistry, Polymer Division, 06800, Ankara, Turkey \\ ${ }^{5}$ Hacettepe University, Institute of Science, Polymer Science and Technology Division, 06800, \\ Ankara, Turkey \\ ${ }^{6}$ Leather and Footwear Research Institute, Collagen Department, 93 Ion Minulescu, 031215, \\ Romania
}

\begin{abstract}
Collagen (C)-poly( $N$-vinyl-2-pyrrolidone) (PVP) double-network superabsorbent hydrogels were synthesized by e-beam (electron beam) radiation processing, both with the addition of water-soluble cross-linking agents (CA), as well as without CA. The aim of the study was to develop a hydrogel for future application as wound dressings via e-beam radiation cross-linking of two biocompatible polymers. The formation of C-PVP hydrogels was confirmed by Fourier transform infrared (FTIR) spectroscopy and their performance was determined from morphological and rheological experiments, such as sol-gel analysis, swelling capacity, storage $\left(G^{\prime}\right)$ and viscous $\left(G^{\prime}\right)$ moduli, cross-linking density, and pore size. Sol-gel analysis was performed in order to determine the gel properties as function of absorbed dose and it was found that the degradation density $\left(p_{0}\right)$ /cross-linking density $\left(q_{0}\right)$ ratio indicates a negligible contribution of chain scission processes. The rheological data confirmed that the elastic properties were predominant: $G^{\prime}$ moduli were larger than $G^{\prime \prime}$ moduli, as is specific to elastic solids and indicate the formation of a permanent hydrogel network

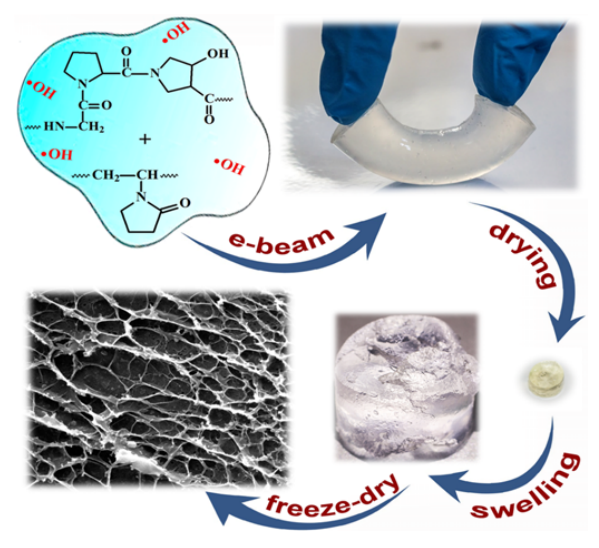
were cross-links are present. Moreover, the swelling studies indicated that the hydrogels have good stability both in deionized water and phosphate-buffered saline (PBS) solution at $37^{\circ} \mathrm{C}$, and superabsorbent properties. The hydrogels network parameters obtained with lower content of $\mathrm{CA}$, could be controlled by changing the absorbed dose.
\end{abstract}

Keywords: e-beam, hydrogels, cross-linking, collagen, PVP.

\section{Introduction}

The growing demand of developing new hydrogels is mainly due to their wide range of applications, namely in hygiene and personal care products, pharmaceuticals and healthcare, food and agriculture, and more recently in tissue engineering and regenerative medicine. Due to the excellent benefits of hydrogels, in recent years a significant increase in the global marketing of these products has been observed. ${ }^{1}$ Of these, cooling and soothing effect on the skin, making hydrogels ideal in burns and painful wounds. They have also been shown to rehydrate the dry wounds, promote the autolytic debridement, facilitates granulation and epithelialisation. ${ }^{2}$

A little known fact is that, most commercial hydrogels used

Acknowledgment: The financial support of INFLPR Nucleus Program under project LAPLAS V is acknowledged.

*Corresponding Author: Viorica Meltzer (viomel@gw-chimie.math.unibuc.ro) as wound dressings are produced by irradiation technologies, either using Co-60 radiation sources ${ }^{3,4}$ or electron beam accelerators. ${ }^{5}$

The radiation cross-linking method of various aqueous polymeric blends (natural or synthetic) is considered the best choice because it offers a number of advantages to both the manufacturer and the final product, as follows: the technology is environmentally friendly (no additional cost regarding waste management, since the cross-linking reaction can be carried out without addition of catalysts or chemical initiators), and in a single technological step it is possible to obtain both the hydrogel formation and its final sterilization. ${ }^{6}$ Radiation cross-linking of single PVP hydrogels ${ }^{7-11}$ or by adding some additives (agar, gelatin, poly(ethylene glycol), citric acid, tartaric acid, persulfate anions) ${ }^{12-19}$ has been extensively investigated. Copolymeric hydrogels based on PVP and other monomers or polymers such as acrylic acid $(\mathrm{AA}){ }^{20-22}$ poly(acrylic acid) (PAA), ${ }^{23,24}$ and in the presence of chemical initiator and/or water-soluble cross-linkers as $\mathrm{N}, \mathrm{N}$-methylen- 
ebis(acrylamide) $(\mathrm{NMBA})^{25-27}$ have been produced using radiation technologies as well as classical synthesis routes. ${ }^{28}$

Radiation cross-linking of collagen hydrogels in the absence or in the presence of chemical initiators and cross-linking agents (CA) has been subjected also to extensive investigations. ${ }^{29-34}$ The interaction between collagen and PVP in blends has been studied by Sionkowska ${ }^{35}$ and further investigated the effects of UV-irradiation on collagen-PVP composition and surface properties. ${ }^{36,37} \gamma$-radiation synthesis of various types of collagen-PVP hydrogels is described by Leyva-Gomez et al., Gonzales-Torres et al., and Demeter et al. ${ }^{38-40}$ The collagen/PVP/PEG hydrogel prepared by $\gamma$-radiation, showed the improvement in fibroblasts viability when the PEG/PVP concentrations were lower. ${ }^{39}$ In our previous study, we have investigated the network structure of collagen-PVP hydrogels produced by $\gamma$-irradiation and we have determined that hydrogels with an elastic character (elastic modulus $\left(G^{\prime}\right)$ larger than viscous modulus $\left(G^{\prime \prime}\right)$ ) were obtained. ${ }^{40}$ However, the in deep investigation on the e-beam radiation synthesis of collagen-PVP based hydrogels is still limited. ${ }^{41}$ E-beam radiation synthesis of polymeric hydrogels offers the advantage of using high dose rates as compared to $\gamma$-irradiation, so the final product is rapidly obtained. Also, the oxidation processes normally induced when a polymeric mixture is exposed for a long time to $\gamma$-irradiation is minimized.

To the best of our knowledge, the e-beam radiation synthesis of C-PVP hydrogels produced in the absence of oxygen, at high dose rate, and in the absence or presence of water soluble cross-linking agents has not been reported. For a target application, the performance of hydrogels should be determined from their morphological and rheological properties, such as swelling capacity, storage and viscous moduli $\left(G^{\prime}\right.$ and $\left.G^{\prime}\right)$, cross-linking density and pore size. ${ }^{42,43}$ The major aim of this paper is to evaluate e-beam radiation synthesis of C-PVP hydrogels in the presence or absence of chemical cross-linking agents (CA), as well as to evaluate the three-dimensional hydrogel network correlated with the absorbed dose. A comprehensive comparison between C-PVP hydrogels produced with or without addition of watersoluble chemical cross-linkers was performed.

\section{Experimental}

\subsection{Materials}

Polyvinylpyrrolidone (PVP360, $M_{W}=3.6 \times 10^{5} \mathrm{~g} / \mathrm{mol}$ ), acrylic acid (AA, assay 99\%, $M_{W}=72.06 \mathrm{~g} / \mathrm{mol}$ ), $N^{\prime} N$-methylenebis(acrylamide) (NMBA, assay 99\%, $M_{W}=154.17 \mathrm{~g} / \mathrm{mol}$ ) and sodium hydroxide ( $\mathrm{NaOH}, 99 \%$ assay, Reag. ACS,) were purchased from Sigma Aldrich (St. Louis, MO, USA). All the chemicals used here were of analytical grade and used without further purification. Type I acidic collagen gel $\left(1 \mathrm{wt} \%, M_{W}=3 \times 10^{5} \mathrm{~g} / \mathrm{mol}\right)$ was extracted from calf hide by the technology currently used in the Collagen Department from Leather and Footwear Research Institute. ${ }^{44}$

\subsubsection{Hydrogels preparation}

In this study six types of C-PVP solutions by varying the PVP concentration, the massic ratio of collagen: PVP, as well as the AA and NMBA concentrations were prepared. The PVP solutions of $5 \%$ and $10 \%(\mathrm{w} / \mathrm{w})$ concentration were prepared in deionised water by mixing with a magnetic stirrer at controlled temperature $\left(80^{\circ} \mathrm{C}\right)$ until complete dissolution. The obtained solutions were kept overnight at room temperature for complete cooling. Corresponding volumes of 5\%, 10\% PVP and 1\% collagen solution were mixed at room temperature as to obtain the desired collagen: PVP volume ratio. To initiate the cross-linking reaction 0.02-0.075 moles of AA, respectively 0.07-0.013 mole of $\mathrm{NaOH}$ were added in the same order. The degree of neutralization of AA was $90 \%$. To these solutions, $2 \%, 1 \%$ and $0.5 \%$ of NMBA were added and well mixed.

\subsubsection{E-beam cross-linking of collagen-PVP hydrogels}

Prior to e-beam irradiation, the samples were placed in plastic syringes and each sample was carefully degassed in an ultrasonic bath and tightly sealed. E-beam irradiation was performed with a $6 \mathrm{MeV}$ linear electron accelerator (ALID 7) owned by the National Institute for Laser, Plasma and Radiation Physics, MăgureleRomania. Irradiation was carried out at an average beam current of $10 \mu \mathrm{A}$, pulse length of $3.75 \mu$ s and pulse repetition rate of $53 \mathrm{~Hz}$. The absorbed doses applied to the samples were 5, 7.5, $10,12.5,25,40 \mathrm{kGy}$ and the average dose rate was $1.88 \mathrm{kGy} / \mathrm{min}$. The dosimetry was performed using a graphite calorimeter (built by our group according to ISO/ASTM 51631:2013). ${ }^{45}$

\subsection{Characterization of collagen-PVP hydrogels}

\subsubsection{Sol-gel analysis}

In order to determine the parameters of e-beam radiation cross-linking in aqueous solution of C-PVP blends with varying content of collagen, PVP and NMBA, sol-gel analysis was performed. Hydrogel samples of $10 \mathrm{~mm}$ diameter were cut into pieces of $5 \mathrm{~mm}$ thickness, dried in a vacuum oven to constant weight and then immersed in deionized water for $48 \mathrm{~h}$ at room temperature $\left(25^{\circ} \mathrm{C}\right)$. After $48 \mathrm{~h}$, the hydrogels were dried again at constant temperature $\left(30^{\circ} \mathrm{C}\right)$ to constant weight. The sol fraction ( $s$-soluble fraction) and gel fraction ( $G$-insoluble fraction, cross-linked hydrogel part) were calculated as:

$$
\begin{aligned}
& s=1-G \\
& G=m_{d} / m_{i} \times 100
\end{aligned}
$$

where $m_{i}$ is the initial mass of dried samples after e-beam irradiation.

The swelling degree (SD) of e-beam cross-linked C-PVP hydrogels was determined gravimetrically by weighting the hydrogels before and after immersion in deionized water (DI) at constant temperature $\left(25^{\circ} \mathrm{C}\right)$ and phosphate buffer solution (PBS, $37^{\circ} \mathrm{C}, \mathrm{pH}=7.4$ ). Since the PBS buffer mimics the physiologically condition (the $\mathrm{pH}$, osmolarity, and ion concentrations) of human body, the stability and swelling capacity of C-PVP hydrogels were studied under these conditions. At the established reading time, the samples were taken out, carefully blotted with filter paper and weighted. The SD has been calculated as a function of the dry $\left(m_{d}\right)$ and swollen $\left(m_{s}\right)$ gel weights using Eq. (3): 
$\operatorname{SD}(\%)=\left(m_{s}-m_{d}\right) / m_{d} \times 100$

For the complete description of the e-beam cross-linking process of aqueous C-PVP solution in the presence of NMBA or without it, the GelSol95 computer software that includes a generalized Charlesby-Pinner equation developed by Charlesby and Rosiak ${ }^{46}$ was used.

$s+\sqrt{s}=\frac{p_{0}}{q_{0}}+\left(2-\frac{p_{0}}{q_{0}}\right)\left(\frac{D_{V}+D_{g}}{D_{V}+D}\right)$

where: $s$-sol fraction [g], $p_{0}$-degradation density, $q_{0}$-cross-linking density, $D$-absorbed dose [kGy], $D_{g}$-gelation dose [kGy], $D_{V}-$ virtual dose $[\mathrm{kGy}]$. Gelation dose $\left(D_{g}\right)$ represents the absorbed dose at which first insoluble gel fraction is obtained. Virtual dose $\left(D_{V}\right)$ describing the dose necessary to transform the real sample into a sample with the molecular weight distribution of $M_{W} / M_{n}=2 .^{47}$

\subsubsection{Dynamic mechanical properties}

Dynamic-mechanical properties of the hydrogels were assessed by oscillatory rheological measurements. Tests were performed using Thermo MARS II Rheometer equipped with plate geometry of $20 \mathrm{~mm}$ diameter. The gap size was set at $0.139 \mathrm{~mm}$ and temperature of $25 \pm 0.5{ }^{\circ} \mathrm{C}$. The mechanical response of hydrogels is expressed as storage or elastic modulus $\left(G^{\prime}\right)$, and viscous or loss modulus $\left(G^{\prime}\right)$, as a function of the frequency. Frequency sweep tests were performed in the linear viscous elastic region (LVR) at frequency values ranging from $0.01-100 \mathrm{rad} \mathrm{s}^{-1}$, at a rate of deformation from 0.1 to $1 \%$, as determined by preliminary strain sweep tests.

\subsubsection{Determination of cross-link density}

In order to characterize the cross-linked structure of the C-PVP hydrogels, the molecular weight between cross-links $\left(M_{C}\right)$, crosslink density $\left(V_{e}\right)$, respectively the mesh size $(\xi)$ were calculated using the rubber elasticity theory. The rubber elasticity theory developed by $\operatorname{Treolar}^{48}$ provides a way to calculate the most important parameters of a cross-linked structure by determining the shear modulus. After swelling experiments, the oscillatory frequency sweep tests were recorded in the LVR region. The average $\bar{G}^{\prime}$ values were used to calculate the $M_{c}, V_{e}$, and $\xi$ values according to Eqs. (5), (6), and (7).

$$
\begin{aligned}
& G^{\prime}=A \frac{\rho}{\bar{M}_{C}} R T\left(V_{r}\right)^{2 / 3}\left(V_{s}\right)^{1 / 3} \\
& V_{e}=\frac{\rho}{\bar{M}_{C}} \\
& \xi=V_{2, s}^{-1 / 3}\left[C_{n}\left(\frac{2 \bar{M}_{C}}{M_{r}}\right)\right]^{1 / 2} \cdot l
\end{aligned}
$$

where $\rho$ is the polymer density $\left[\mathrm{kg} \mathrm{m}^{-3}\right], M_{C}$ is the molecular weight between cross-links of the hydrogels chains $\left[\mathrm{kg} \mathrm{mol}^{-1}\right]$, $R$ is universal gas constant $\left[8.314 \mathrm{~m}^{3} \mathrm{~Pa} \mathrm{~mol}^{-1} \mathrm{~K}^{-1}\right]$, T is the absolute experimental temperature $\left[298.15^{\circ} \mathrm{K}\right] ; V_{r}$ is the polymer volume fraction after e-beam cross-linking, $V_{s}$ is the polymer volume fraction of the cross-linked hydrogel in swollen state. According with Mark and Erman, ${ }^{49}$ the factor $A$ equals 1 for an affine network. $C_{n}$ is the Flory characteristic ratio. This was taken as a weighted average of the characteristic ratios of the polymers, Collagen $=9,^{50} \mathrm{PVP}=12.3^{51} l$ is the carbon-carbon bond length $(0.154 \mathrm{~nm}) . M_{r}$ is the monomeric unit of PVP and collagen, taken as an average (PVP=112.88 $\mathrm{g} \mathrm{mol}^{-1}$ and Collagen= $\left.321.32 \mathrm{~g} \mathrm{~mol}^{-1}\right)$. The polymer volume fractions $\left(V_{r}\right.$ and $\left.V_{s}\right)$ were determined with Eq. (8).

$1 / V_{r}(s)=\left(1+\rho / \rho_{w}\left(w^{-1}-1\right)\right)$

where $\rho$ and $\rho_{w}$ are the densities of swollen hydrogel in equilibrium state and water $\left[\mathrm{kg} \mathrm{m}^{-3}\right], w$ is the weight of the hydrogel after e-beam cross-linking, respectively after swelling. By conducting sol-gel analysis and oscillatory frequency sweep tests, as described in the above section it was also possible to determine the radiation-chemical yields of cross-linking, $G(X)$, as well as radiation-chemical yields of chain scission, $\mathrm{G}(\mathrm{S})$, on the basis of Eqs. (9) and (10). The $G(X)$ is related to the molecular weight between cross-links, $M_{C}\left[\mathrm{~kg} \mathrm{~mol}^{-1}\right]$, polymer concentration in irradiated solution, $c[\mathrm{~g} / \mathrm{L}]$ and the absorbed dose $[\mathrm{Gy}]{ }^{52}$

$G_{X}=\left(4.9 \times 10^{2} \times c\right) /\left(M_{C} \times D \times \rho\right)$

$G_{S} / G_{X}=2 p_{0} / q_{0}$

\subsubsection{Fourier Transform Infrared Spectra (FTIR)}

Chemical modification occurring upon e-beam irradiation was assessed by FTIR. FTIR analysis of unirradiated and irradiated C-PVP hydrogels was carried out with Perkin Elmer-Spectrum 100 instrument equipped with ATR diamond crystal plate. After the sol fraction was removed, the hydrogels samples were dried out until constant weight and used for FTIR investigations. Spectra were acquired in ATR mode and each spectrum consisted of 20 scans per sample, in the $4000-600 \mathrm{~cm}^{-1}$ wavenumbers range and a resolution of $4 \mathrm{~cm}^{-1}$. The registered FTIR spectra were processed by applying normalization and ATR correction available on the Spectrum v.6.3.2 software.

\subsubsection{Scanning Electron Microscopy (SEM)}

The morphology of C-PVP hydrogels was observed by using a scanning electron microscope (SEM) FEI Inspect S model (FEI Co. Ltd.) operating at an accelerating voltage of $20 \mathrm{kV}$. The hydrogel samples were swollen to equilibrium in phosphate buffer solution (PBS) at $\mathrm{pH}=7.4$ followed by lyophilisation. The cross-section of freeze-dried hydrogel samples was observed after gold coating. The SEM images were taken at magnifications of 200X, $500 \mathrm{X}$, respectively $50000 \mathrm{X}$.

\section{Results and discussion}

\subsection{Sol-gel analysis}

Figure 1 depicts changes in the gel fraction (GF) as function of absorbed dose of e-beam processed C-PVP hydrogels with different collagen: PVP massic ratios and without addition of CA. Depending on collagen content, the gelation started below target irradiation dose. The hydrogels samples prepared with $0.5 \%$ $(\mathrm{w} / \mathrm{w})$ collagen and $2.5 \%(\mathrm{w} / \mathrm{w})$ PVP (samples coded as 2_C$\mathrm{PVP})$, required a higher gelation dose of $4.15 \mathrm{kGy}$. The hydro- 

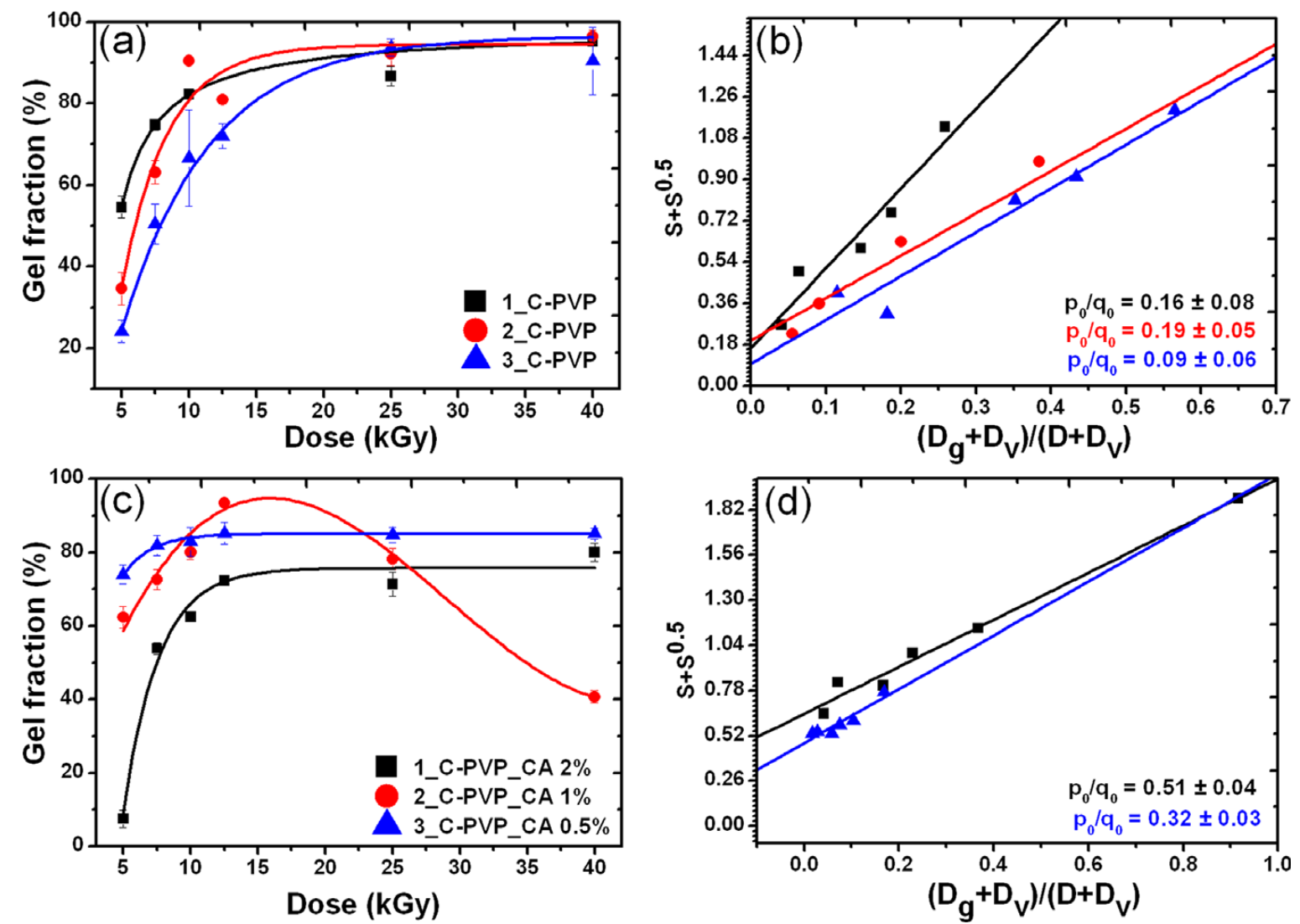

Figure 1. (a) Gel fraction as a function of absorbed dose during e-beam irradiation for C-PVP hydrogels without CA; (b) Sol-gel data plotted in coordinates corresponding to Charlesby-Pinner equation Eq. (4); (c) Gel fraction as a function of absorbed dose during e-beam irradiation for C-PVP_CA hydrogels; (d) Sol-gel data plotted in co-ordinates corresponding to Charlesby-Pinner equation Eq. (4).

gels samples prepared with $0.7 \%$ and $0.3 \%(\mathrm{w} / \mathrm{w})$ of collagen, respectively $1.5 \%$ and $3.5 \%(\mathrm{w} / \mathrm{w})$ of PVP (1_C-PVP and 3_C-PVP), required a smaller gelation dose, less than $3.9 \mathrm{kGy}$. The GF increased with the absorbed dose up to $12.5 \mathrm{kGy}$, were this parameter had lowest value, however after increasing of absorbed dose, the GF constantly increased in correspondence with absorbed dose. As is shown in the Figure 1(a), the gelation percentages at the minimum target irradiation dose ( $5 \mathrm{kGy}$ ) were found to increase with the PVP content. At the maximum absorbed dose of $40 \mathrm{kGy}$, the GF reached up to $96 \%$, for C-PVP hydrogels with $0.5 \%(\mathrm{w} / \mathrm{w})$ collagen and $2.5 \%(\mathrm{w} / \mathrm{w})$ PVP. As is stands above, the evaluation of e-beam cross-linking process for C-PVP hydrogels synthesized without $\mathrm{CA}$ was followed by determination of degradation vs. cross-linking density ratio according with Eq. (4). The proportion of radiation yield of degradation (scission) to radiation yield of cross-linking expressed as $p_{0} / q_{0}$ quantifies the relation between the cross-linking and degradation processes. ${ }^{53}$ In this case, we found that $p_{0} / q_{0}$ ratios were lower for hydrogels with higher content of PVP $(3.5 \%, w / w)$. When the collagen content was $0.5-1 \%(\mathrm{w} / \mathrm{w})$, the $p_{0} / q_{0}$ ratios ranged between 0.16 and 0.19 , which suggests that cross-linking processes predominated. As can been seen in the Table 2 , also the radio-chemical yield of cross-linking, $\mathrm{G}(\mathrm{X})$ were greater than radio-chemical yields of scission, $\mathrm{G}(\mathrm{S})$.

Figure 1(c) and (d) shows the gel properties as function of absorbed dose determined for C-PVP hydrogels prepared in presence of various contents of AA, respectively $N^{\prime} N$-methylenebis(acrylamide) (NMBA) added as cross-linker and to improve the e-beam cross-linking reaction. The gel point started to shows below the target irradiation dose of $5 \mathrm{kGy}$ and the required absorbed dose to reach this point has decreased. For the hydrogels containing 0.02 moles $\mathrm{AA}$ and $0.5 \% \mathrm{NMBA}$, the gelation dose

Table 1. Hydrogels composition and sol-gel parameters calculated according Charlesby-Pinner equation (Eq. (4))

\begin{tabular}{|c|c|c|c|c|c|c|c|}
\hline \multirow{2}{*}{ Sample codification } & \multicolumn{4}{|c|}{ Hydrogels Composition } & \multicolumn{3}{|c|}{ Sol-Gel Parameters } \\
\hline & Collagen (\%) & PVP (\%) & AA (mole) & NMBA (\%) & $p_{0} / q_{0}$ & $D_{g}(\mathrm{kGy})$ & $D_{V}(\mathrm{kGy})$ \\
\hline 1_C-PVP & 0.7 & 1.5 & - & - & 0.16 & 3.23 & -1.54 \\
\hline 2_C-PVP & 0.5 & 2.5 & - & - & 0.19 & 4.15 & -2.06 \\
\hline 3_C-PVP & 0.3 & 3.5 & - & - & 0.09 & 3.90 & 0.77 \\
\hline 1_C-PVP_CA 2\% & 0.7 & 3 & 0.075 & 2 & 0.51 & 4.86 & -3.33 \\
\hline 2_C-PVP_CA 1\% & 0.5 & 5 & 0.05 & 1 & 0.79 & 3.96 & -3.91 \\
\hline 3_C-PVP_CA 0.5\% & 0.3 & 7 & 0.02 & 0.5 & 0.31 & 1.70 & -1.03 \\
\hline
\end{tabular}


was observed to decrease significantly, at doses below 2 kGy (Table 1).

For those C-PVP blends prepared with $0.3-0.5 \%(\mathrm{w} / \mathrm{w})$ collagen, respectively 5-7\% (w/w) PVP, the GF percentages was more than $60 \%$ gelation achieved even at $5 \mathrm{kGy}$. The gelation of 1_C-PVP_CA 2\% system not increased too much after $12.5 \mathrm{kGy}$, but requested higher absorbed dose in order to reach $80 \% \mathrm{GF}$. The GF (\%) of 2_C-PVP_CA 1\% hydrogels samples, start to decrease drastically over $12.5 \mathrm{kGy}$ absorbed dose. When PVP concentration was increased at $7 \%(\mathrm{w} / \mathrm{w})$ and the concentration of $\mathrm{AA}$ and CA were decreased at 0.02 moles, respectively at $0.5 \%(\mathrm{w} / \mathrm{w})$, we observed a significant increase in GF (\%) in relation with the absorbed dose, above $75 \%$ at $5 \mathrm{kGy}$. The $p_{0} / q_{0}$ ratios were found to be 0.32 and 0.51 . For hydrogels with $0.5 \%(\mathrm{w} / \mathrm{w})$ collagen and $5 \%(\mathrm{w} / \mathrm{w}) \mathrm{PVP}$, the $p_{0} / q_{0}$ ratio was found to be 0.79 . In our previous study, we reported a $p_{0} / q_{0}$ ratio of 0.14 for C-PVP hydrogels processed by $\gamma$-irradiation in the absence of air and without $\mathrm{CA}^{40}$ For polymer blends which form insoluble fractions upon radiation cross-linking the $p_{0} / q_{0}$ ratio is less than 2 , indicating that the cross-linking processes predominated ${ }^{53}$ Considering the above, for C-PVP hydrogels prepared without addition of CA, the found values of the $p_{0} / q_{0}$ ratio indicate a negligible contribution of chain scission processes. For C-PVP hydrogels produced in the presence of $2 \%(\mathrm{w} / \mathrm{w})$ of $\mathrm{CA}$, the $p_{0} / q_{0}=0.79$ and $0.51(1 \% \mathrm{CA}, \mathrm{w} / \mathrm{w})$ indicate rather presence of chain scission processes, which is in accordance with the calculated values of $\mathrm{G}(\mathrm{X})$ and $\mathrm{G}(\mathrm{S})$ (Table 2).

However, the addition of CA, has influenced the C-PVP crosslinking process, since the $p_{0} / q_{0}$ ratios were considerably higher as compared with values determined for C-PVP hydrogels without CA. As the concentration of CA is higher, the correspondent gelation dose $\left(D_{g}\right)$ is higher (Table 1$)$. The same behaviour was observed for some hydrogel dressings based on chitosan and PVP prepared in the presence of lactic acid and subjected to ionizing radiations. ${ }^{53}$ For the hydrogel coded as 3_C-PVP_CA 0.5\% was obtained the highest GF above $87.2 \%$ at the absorbed dose of $7.5 \mathrm{kGy}$, but decreased slowly with the increase of radiation dose up to $82 \%$. For the investigated C-PVP hydrogels, the virtual doses $\left(D_{v}\right)$ were found to be negative. This can be assigned to the fact that the molecular weight distribution of the prepared systems does not follow a Gaussian distribution. Usually, the radiation processing of polymeric materials is comprised of two processes: cross-linking and degradation; thus for a proper assessment of the irradiation process, determining the radia- tion-chemical yields of cross-linking $\mathrm{G}(\mathrm{X})$ and chain scission $\mathrm{G}(\mathrm{S})$ is necessary. The radiation-chemical yields were determined using the values of molecular weight between cross-links $\left(M_{C}\right)$ obtained from the oscillatory frequency sweep tests using eqs. (9) and (10). For e-beam processed C-PVP hydrogels without CA, the values of radiation-chemical yields are presented in Table 1. The calculated $\mathrm{G}(\mathrm{X})$ values ranged between $0.03-10.74 \times 10^{-4}$ $\mathrm{mol}^{-1}$ and decreased with the absorbed dose, but were considerably higher than radiation-chemical yields of chain scission G(S) and strongly depended on the hydrogels composition. In our previous study related to the preparation of collagen-PVP hydrogels by $\gamma$-radiation technique, we reported a maximum value of $\mathrm{G}(\mathrm{X})$ about $3.65 \times 10^{-8} \mathrm{~mol} \mathrm{~J}^{-1}$. $^{40}$ In comparison with the former study, the newly obtained hydrogels presented higher radiation-chemical yields of cross-linking. In Table 3 the radiationchemical yields of C-PVP hydrogels prepared with CA are presented, were the highest value of $\mathrm{G}(\mathrm{X})$ was found to be $1.07 \mathrm{~mol}$ $\mathrm{J}^{-1}$ at $5 \mathrm{kGy}$ for the hydrogel 1_C-PVP NMBA $2 \%$. As can be seen in Table 2, for hydrogels prepared in the presence of $2 \%$ and $1 \%(\mathrm{w} / \mathrm{w}) \mathrm{CA}$, the values of $\mathrm{G}(\mathrm{X})$ and $\mathrm{G}(\mathrm{S})$ were comparable, $\mathrm{G}(\mathrm{X}) \approx \mathrm{G}(\mathrm{S})$ or $\mathrm{G}(\mathrm{S})>\mathrm{G}(\mathrm{X})$. This has been attributed to the fact that chain scission prevails instead of the cross-linking processes.

For C-PVP hydrogels prepared with low concentration of cross-linking agents (3_C-PVP_CA 0.5\%), the radiation-chemical yield of cross-linking, $\mathrm{G}(\mathrm{X})$, exceeds the processes of chain scission, and the highest value was obtained at $7.5 \mathrm{kGy}$. Above this dose, the radiation-chemical yield of cross-linking remains almost constant, but starting with $25 \mathrm{kGy}$ decreased. In our previous study, related to the $\gamma$-radiation processing of natural polymers in solution or solid state, was demonstrated that the dose rate, as well as the concentration of polymers are critical parameters which influenced the final results of radiation processing of natural polymers. ${ }^{54,55}$ At the same time, the irradiation conditions also influence the results of irradiations. Very low dose rates will enhance the oxidative degradation processes during irradiation.

\subsection{Swelling experiments}

The swelling capacity is a direct indication of hydrogels capacity to absorb large amounts of water, saline solution or physiological fluids. Therefore, the swelling properties of C-PVP hydrogels were tested both in deionized water, as well as in phosphate buffer solution (PBS, $37^{\circ} \mathrm{C}, \mathrm{pH}=7.4$ ). In Figure 2 the swelling

Table 2. Radiation-chemical yield of cross-linking G(X) and chain scission G(S) calculated for C-PVP hydrogels

\begin{tabular}{|c|c|c|c|c|c|c|c|c|c|c|c|c|}
\hline \multirow{3}{*}{ Sample codification } & \multicolumn{6}{|c|}{$\mathrm{G}(\mathrm{X}) \times 10^{-4} \mathrm{~mol} \mathrm{~J}^{-1}$} & \multicolumn{6}{|c|}{$\mathrm{G}(\mathrm{S}) \times 10^{-4} \mathrm{~mol} \mathrm{~J}^{-1}$} \\
\hline & \multicolumn{6}{|c|}{ Absorbed dose (kGy) } & \multicolumn{6}{|c|}{ Absorbed dose (kGy) } \\
\hline & 5 & 7.5 & 10 & 12.5 & 25 & 40 & 5 & 7.5 & 10 & 12.5 & 25 & 40 \\
\hline 1_C-PVP & 3.88 & 2.49 & 3.26 & 1.61 & 0.68 & 0.28 & 1.24 & 0.79 & 1.04 & 0.52 & 0.22 & 0.09 \\
\hline 2_C-PVP & 6.47 & 3.25 & 1.73 & 1.27 & 1.22 & 0.58 & 2.46 & 1.23 & 0.65 & 0.48 & 0.46 & 0.20 \\
\hline \multirow[t]{2}{*}{ 3_C-PVP } & 10.74 & 3.48 & 1.94 & 1.73 & 0.53 & 0.13 & 1.93 & 0.63 & 0.35 & 0.31 & 0.11 & 0.03 \\
\hline & \multicolumn{6}{|c|}{$\mathrm{G}(\mathrm{X}) \mathrm{mol} \mathrm{J}^{-1}$} & \multicolumn{6}{|c|}{$\mathrm{G}(\mathrm{S}) \mathrm{mol} \mathrm{J}^{-1}$} \\
\hline 1_C-PVP_CA $2 \%$ & 1.07 & 0.94 & 1.12 & 1.14 & 0.25 & 0.07 & 1.09 & 0.96 & 1.15 & 1.16 & 0.25 & 0.08 \\
\hline 2_C-PVP_CA 1\% & 1.01 & 0.54 & 0.37 & 0.20 & 0.12 & 0.06 & 1.60 & 0.85 & 0.59 & 0.31 & 0.19 & 0.09 \\
\hline 3_C-PVP_CA $0.5 \%$ & 0.23 & 0.25 & 0.13 & 0.10 & 0.14 & 0.08 & 0.15 & 0.16 & 0.09 & 0.03 & 0.09 & 0.05 \\
\hline
\end{tabular}



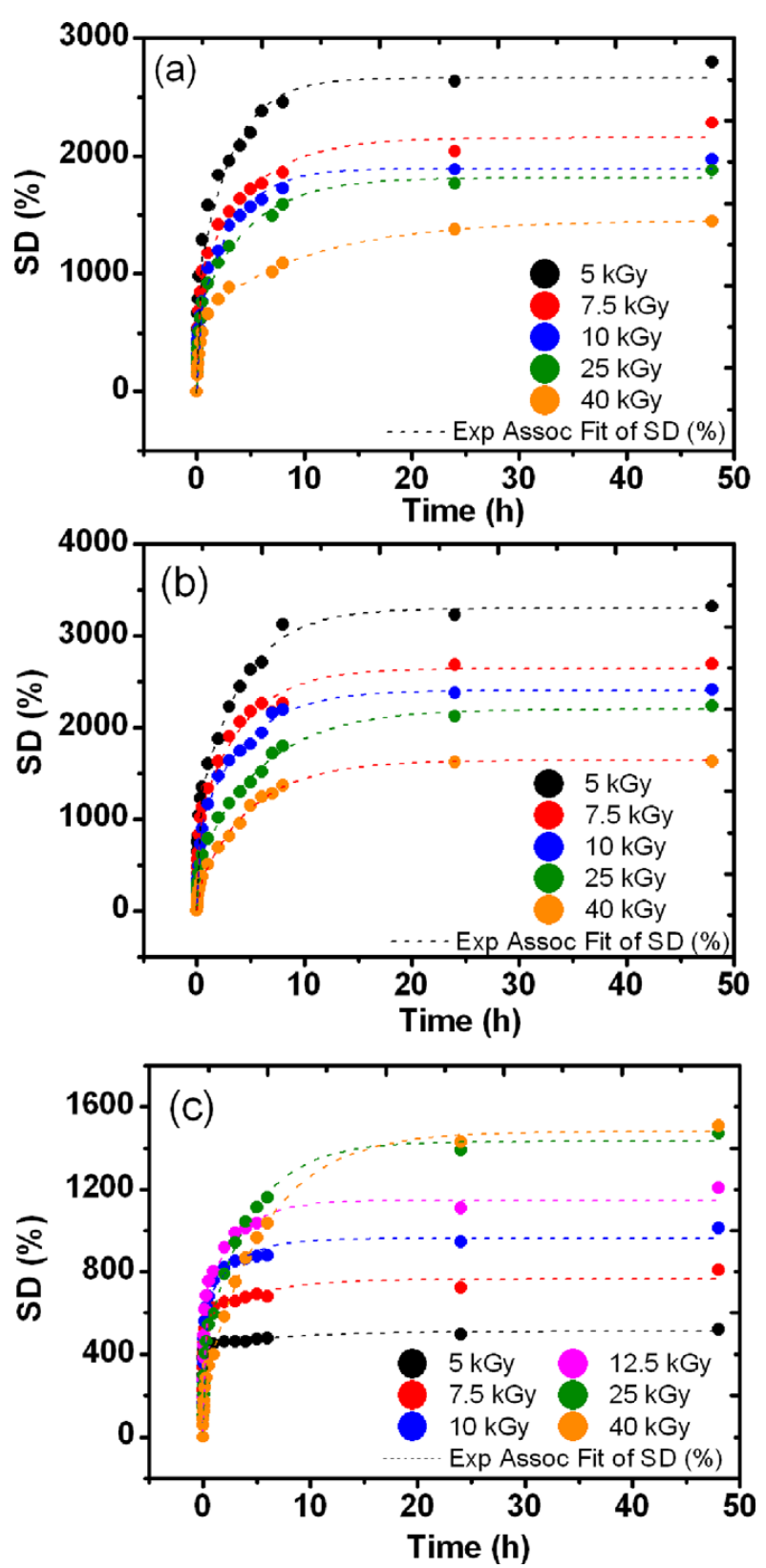

Figure 2. Equilibrium swelling degree (SD) vs. immersion time and absorbed dose in DI water for e-beam processed collagen-PVP hydrogels without cross-linking agents. The solid symbols indicate the swelling ratio at the established reading time and the dashed lines are fitted according to ExpAssoc.

capacity of C-PVP hydrogels obtained without adding NMBA, as $\mathrm{CA}$ is presented. The percentage of swelling capacity was higher if the total concentration of hydrogel components was lower and reached a value above $3000 \%$ for hydrogels obtained at $5 \mathrm{kGy}$. Regarding the evolution of swelling capacity as function of absorbed dose, this parameter decreased as absorbed dose increased. An increase in the concentration of PVP in the studied hydrogels resulted in the reduction of swelling capacity, below $1500 \%$ (Figure 2(c)). On the contrary with 1_C-PVP and 2_C-PVP hydrogels (Figure 2(a), (b)), the swelling capacity of 3_C-PVP hydrogels has increased with the increase in absorbed dose.

In Figure 3(a), (b) the swelling capacity of e-beam C-PVP cross-linked in the presence of $0.5 \%$ NMBA is shown. Herein,
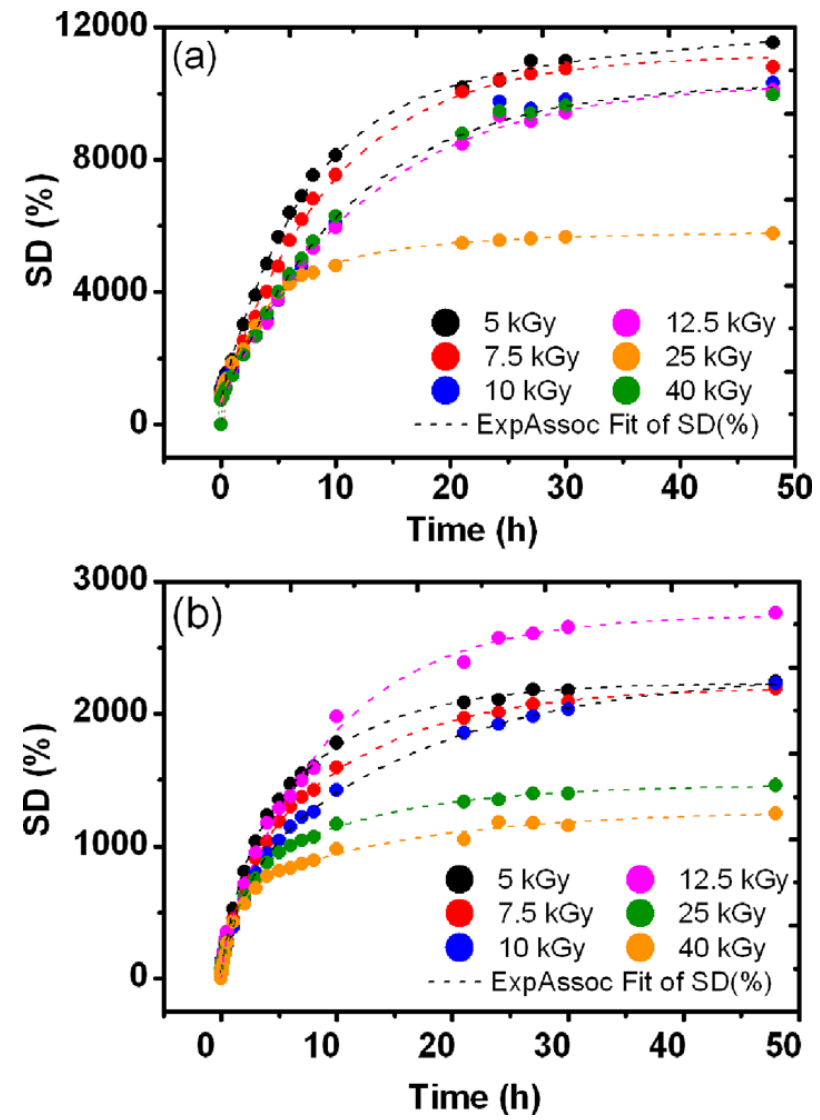

Figure 3. Equilibrium swelling degree (SD) vs. immersion time and absorbed dose in de-ionized (DI) - (a) and PBS $\left(37^{\circ} \mathrm{C}\right)$ - (b) for e-beam processed C-PVP hydrogels with CA. The solid symbols indicate the swelling ratio at the established reading time and the dashed lines are fitted according to ExpAssoc.

we observed a massive increasing in swelling capacity from $1000 \%$ to $11000 \%$ as the concentration of CA was decreased. For C-PVP hydrogels prepared with 1-2\% NMBA, respectively 0.05-0.075 moles of AA, no obvious evidence as function of absorbed dose was observed. On the other hand, for C-PVP hydrogels synthesized at $0.5 \% \mathrm{CA}$, an obvious trend of the swelling capacity was observed as function of absorbed dose, were at $25 \mathrm{kGy}$, respectively $40 \mathrm{kGy}$, this parameter has decreased considerably. Figure 3(b) presents the swelling capacity of C-PVP hydrogels in phosphate buffer solution (PBS, $37^{\circ} \mathrm{C}, \mathrm{pH}=7.4$ ) as function of absorbed dose. The hydrogel presented stability over $48 \mathrm{~h}$ in PBS solution, but the total swelling power was reduced up to $2500 \%$. In this case, the SD (\%) decreased according with the applied radiation dose, at $5 \mathrm{kGy}, 10 \mathrm{kGy}, 25-40 \mathrm{kGy}$ due to the increasing of cross-linking points in the hydrogel network. The same behaviour was identified when the network parameters were investigated, more exactly the $M_{C}$ (molecular weight between cross-links) has decreased and the cross-linking density has increased. When the hydrogel was irradiated at $12.5 \mathrm{kGy}$, the SD (\%) increased and the correspondent value of $M_{C}$, increased as well. In the range 10-12.5 kGy, the hydrogel properties were similar. The values of elastic moduli $(G)$ were also similar $(2800$ $\mathrm{Pa}$ at $10 \mathrm{kGy}$ and $2500 \mathrm{~Pa}$ at $12.5 \mathrm{kGy}$ ). These small reduction of $G^{\prime}$ modulus can be the consequence of a higher absorbency power, thus it is obvious that when absorbed dose increased two 
fold, the elastic character of hydrogels has increased accordingly. The significant decrease in swelling capacity of hydrogels in PBS solution compared to the values in DI water is due to the osmotic pressure caused by unequal distribution of ions in the medium and the hydrogel network. The ions attached to the polymer network can be considered locked in place and separated from the external solution through a semi-permeable membrane. When the swelling takes place in pure water, the maximum osmotic pressure develops and the maximum swelling values are obtained. ${ }^{56}$ In order to have a better understanding of the swelling process, the experimental data were fitted to an exponential equation: $y=y_{0}+A 1 *\left(1-\exp \left(-x / t_{1}\right)\right)+A 2 *\left(1-\exp \left(-x / t_{2}\right)\right)$, represented in Figure 2 and Figure 3 with dashed lines. The minimum coefficient of determination $\left(R^{2}\right)$ was 0.9833 .

\subsection{Dynamic mechanical properties}

In order to follow a complete analysis of e-beam processed CPVP hydrogels without CA, as well as the influence of CA on the hydrogel properties, rheological characterization was carried out and the results are shown in Figure 4. $G^{\prime}$ and $G^{\prime \prime}$ values are also reported in Tables 3 and 4 . The dynamic storage modulus $(G)$ and viscous modulus $\left(G^{\prime}\right)$ were utilized to examine the stability and viscoelastic character of C-PVP hydrogels in the LVR region, as well as to establish the influence of absorbed dose and the presence or absence of CA on the storage and viscous moduli magnitude. Among other properties, the evaluation of $G^{\prime}$ and $G^{\prime \prime}$ moduli of soft materials like hydrogels designed for wound dressing application is mandatory. Due to their viscoelastic character, these materials do not store only elastic energy when an external force is applied, but also dissipate energy like a viscous fluid. The linear response of storage modulus $\left(G^{\prime}\right)$ up to a certain limit of strain shows that the strength of the new formed crosslinked network in the hydrogel opposes the external force and maintains equilibrium. Contrary, when the strain increase to a high level, the chemical bonds within hydrogel network are broken or start to deform, the hydrogels lose the elasticity, thus developing a viscous character. When this viscous character is predominant, the viscous modulus $\left(G^{\prime}\right)$ should be always larger than the storage modulus $(G) .{ }^{57}$ As can be seen in the investigated angular frequency range, the $G^{\prime}$ values are higher than the corresponding $G^{\prime \prime}$ values. $G^{\prime}$ being larger than $G^{\prime \prime}$ reflects a dominant elastic character specific to elastic solids ${ }^{58}$ and suggests that the hydrogels obtained by e-beam processing in these conditions form a permanent network due to cross-links. ${ }^{59-61}$ The magnitude of the storage and viscous moduli $\left(G^{\prime}\right)$ and $\left(G^{\prime}\right)$ was depended on the hydrogel composition, namely of collagen and PVP concentration, as well as of CA (Figure 4). For those hydrogels prepared in the absence of CA, the $G^{\prime}$ values do not exceed $66.5 \mathrm{~Pa}$, in contrast with the hydrogels prepared with various concentrations of CA, were the $G^{\prime}$ values ranged between 1800 $-14100 \mathrm{~Pa}$. Looking closer at the evolution of the $G^{\prime}$ and $G^{\prime \prime}$ moduli as function of absorbed dose, every hydrogels composition has presented independent rheological behavior. For C-PVP hydrogels without CA (1_C-PVP), the $G^{\prime}$ and $G^{\prime \prime}$ values tend to increase up to $10 \mathrm{kGy}$, followed by a reduction of these parameters as radiation dose is increased. At the same time, the hydrogel noted as 2_C-PVP, presented a $G^{\prime}$ parameter that was almost constant up to $12.5 \mathrm{kGy}$, and increased two fold at $40 \mathrm{kGy}$. The hydrogel 3_C-PVP (Figure 4(c)), presented the highest $G^{\prime}$ and $G^{\prime \prime}$ values at $5 \mathrm{kGy}$, however at a higher level of radiation dose ( $40 \mathrm{kGy}$ ), an accentuated decrease of elastic and viscous moduli about ten folds was observed. The increase of the $G^{\prime}$ value as a consequence of absorbed dose can be attributed to the increase of

Table 3. Storage modulus $\left(G^{\prime}\right)$, viscous modulus $\left(G^{\prime}\right)$, the molecular weight between cross-links of the hydrogels chains $\left(M_{C}\right)$, the crosslink density $\left(V_{e}\right)$ and network mesh size $(\xi)$ of C-PVP hydrogels prepared without CA

\begin{tabular}{|c|c|c|c|c|c|c|c|c|c|c|c|c|c|c|c|}
\hline \multirow[b]{2}{*}{ Dose $^{a}$} & \multicolumn{5}{|c|}{ 1_C-PVP } & \multicolumn{6}{|c|}{ 2_C-PVP } & \multicolumn{4}{|c|}{ 3_C-PVP } \\
\hline & $\bar{G}^{\prime b}$ & $\bar{G}^{\prime \prime c}$ & $M_{C}^{d}$ & $V_{e}^{e}$ & $\xi^{f}$ & $\bar{G}^{\prime b}$ & $\bar{G}^{\prime \prime c}$ & $M_{C}{ }^{d}$ & $\overline{V_{e}^{e}}$ & $\xi^{f}$ & $\bar{G}^{\prime b}$ & $\bar{G}^{\prime \prime c}$ & $M_{C}^{d}$ & $V_{e}^{e}$ & $\xi^{f}$ \\
\hline 5 & 10.7 & 0.9 & 5201 & 0.210 & 327 & 12.1 & 1.4 & 3372 & 0.300 & 336 & 66.5 & 4.5 & 1979 & 0.524 & 157 \\
\hline 7.5 & 13.3 & 1.6 & 5620 & 0.187 & 318 & 13.7 & 1.2 & 4415 & 0.232 & 317 & 28.4 & 2.0 & 4127 & 0.248 & 274 \\
\hline 10 & 24.3 & 2.5 & 3292 & 0.312 & 242 & 15.2 & 0.7 & 6135 & 0.169 & 373 & 19.7 & 0.9 & 5589 & 0.182 & 337 \\
\hline 12.5 & 13.4 & 1.4 & 5188 & 0.203 & 314 & 12.2 & 0.8 & 6634 & 0.157 & 376 & 19.5 & 2.5 & 5054 & 0.200 & 345 \\
\hline 25 & 13.2 & 1.0 & 6318 & 0.162 & 334 & 17.4 & 1.24 & 3560 & 0.285 & 304 & 12.6 & 0.4 & 7557 & 0.134 & 417 \\
\hline 40 & 8.3 & 1.0 & 9265 & 0.113 & 371 & 29.5 & 4.5 & 5030 & 0.207 & 229 & 4.8 & 1.3 & 21737 & 0.046 & 626 \\
\hline
\end{tabular}

${ }^{a}$ Dose (kGy). ${ }^{b, c} G^{\prime}, G^{\prime \prime}(\mathbf{P a}) \cdot{ }^{d} M_{C}\left(\mathrm{~kg} \mathrm{~mol}^{-1}\right) \cdot{ }^{e} V_{e}\left(\mathrm{~mol} \mathrm{~m}^{-3}\right) \cdot{ }^{f} \xi(\mathrm{nm})$.

Table 4. Storage modulus $\left(G^{\prime}\right)$, viscous modulus $\left(G^{\prime}\right)$, the molecular weight between cross-links of the hydrogels chains $\left(M_{C}\right)$, the crosslink density $\left(V_{e}\right)$ and network mesh size ( $\xi$ ) of C-PVP hydrogels prepared with different concentrations of CA

\begin{tabular}{|c|c|c|c|c|c|c|c|c|c|c|c|c|c|c|c|}
\hline & \multicolumn{5}{|c|}{ 1_C-PVP_CA $2 \%$} & \multicolumn{5}{|c|}{ 2_C-PVP_CA 1\% } & \multicolumn{5}{|c|}{ 3_C-PVP_CA $0.5 \%$} \\
\hline Dose $^{a}$ & $\bar{G}^{\prime b}$ & $\overline{\bar{G}^{\prime \prime c}}$ & $M_{C}^{d}$ & $V_{e}^{e}$ & $\xi^{f}$ & $\bar{G}^{\prime b}$ & $\bar{G}^{\prime \prime c}$ & $M_{C}^{d}$ & $V_{e}^{e}$ & $\xi^{f}$ & $\bar{G}^{\prime b}$ & $\bar{G}^{\prime \prime c}$ & $M_{C}{ }^{d}$ & $\overline{V_{e}^{e}}$ & $\xi^{f}$ \\
\hline 5 & 5.4 & 1.3 & 46 & 22.63 & 26 & 6.4 & 0.9 & 29 & 35.89 & 25 & 1.8 & 0.13 & 71 & 14.14 & 59 \\
\hline 7.5 & 6.5 & 1.4 & 35 & 29.14 & 25 & 5.2 & 0.8 & 36 & 27.73 & 28 & 3.2 & 0.51 & 45 & 22.14 & 47 \\
\hline 10 & 11.2 & 9.8 & 23 & 44.54 & 18 & 4.5 & 1.4 & 39 & 25.55 & 30 & 2.8 & 0.52 & 60 & 17.14 & 53 \\
\hline 12.5 & 14.1 & 7.6 & 18 & 57.67 & 17 & 3.8 & 0.8 & 58 & 17.71 & 36 & 2.5 & 0.56 & 66 & 15.55 & 54 \\
\hline 25 & 5.9 & 1.2 & 40 & 26.37 & 26 & 3.9 & 0.7 & 47 & 21.53 & 36 & 7.8 & 1.03 & 24 & 41.50 & 27 \\
\hline 40 & 3.2 & 1.3 & 82 & 12.66 & 33 & 3.5 & 1.0 & 65 & 15.47 & 39 & 8.4 & 1.51 & 25 & 40.10 & 26 \\
\hline
\end{tabular}

${ }^{a}$ Dose $(\mathrm{kGy}) .{ }^{b, c} G^{\prime}, G^{\prime \prime}(\mathbf{k P a}) \cdot{ }^{d} M_{C}\left(\mathrm{~kg} \mathrm{~mol}{ }^{-1}\right) \cdot{ }^{e} V_{e}\left(\mathrm{~mol} \mathrm{~m}^{-3}\right) \cdot{ }^{f} \xi(\mathrm{nm})$. 

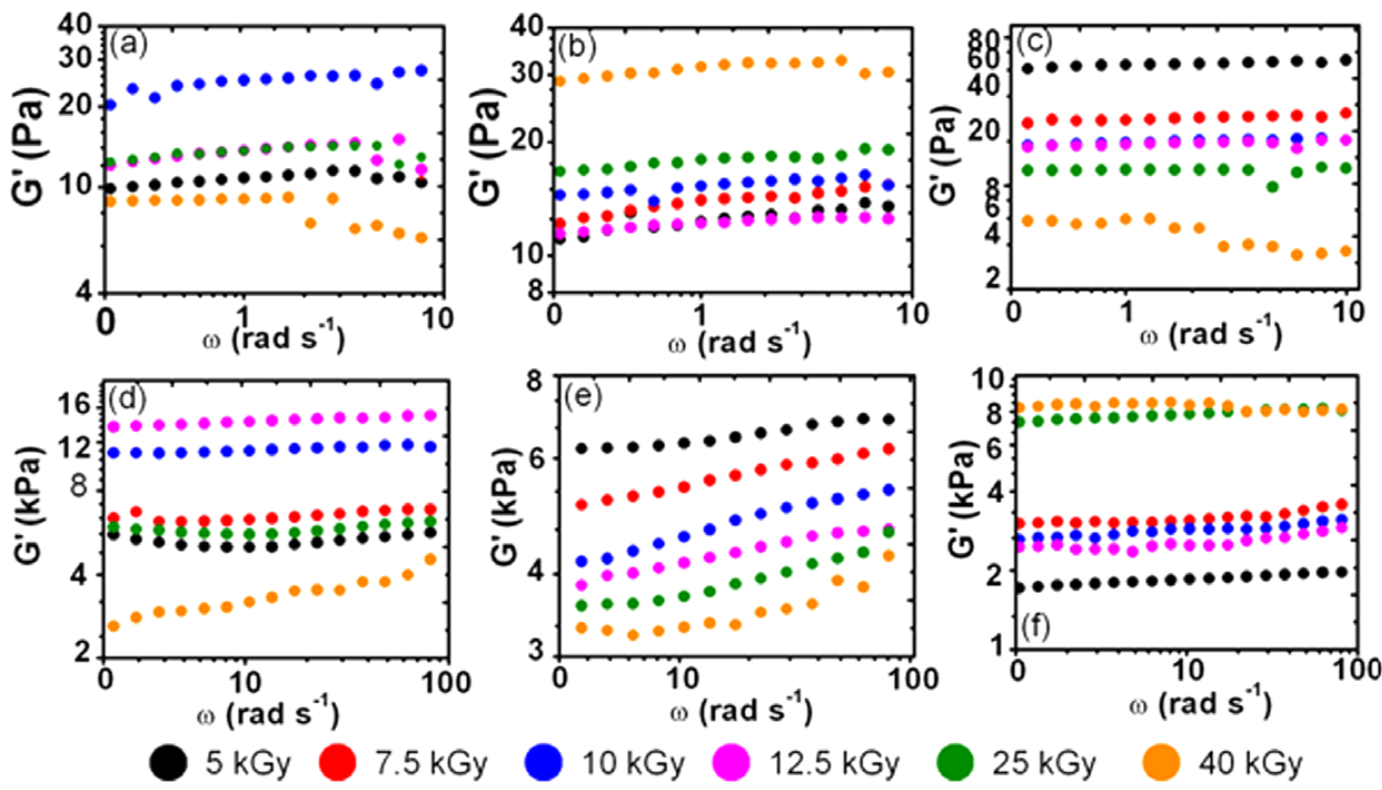

Figure 4. Storage modulus $\left(G^{\prime}\right)$, as function of the angular frequency of C-PVP hydrogels and their evolution as function of absorbed dose. (a), (b), and (c); Oscillatory rheology of the C-PVP hydrogels prepared without CA. (d), (e), and (f); Oscillatory rheology of the C-PVP hydrogels prepared with CA.

cross-link density, ${ }^{62}$ opposing a decrease in the storage modulus as function of absorbed dose can be associated with the degradation of hydrogel network. In our previous work, it was demonstrated that when $G^{\prime \prime}$ became larger than $G^{\prime}$, viscous behaviour became dominant due to the significant decrease in molecular weight with dose. ${ }^{54}$

In Figure 4(d), (e), and (f) the rheological behaviour of C-PVP hydrogels prepared with different concentrations of CA is presented. The magnitudes of storage and viscous moduli depend on the CA concentration, the hydrogels composition as well as on the applied absorbed dose. The hydrogels prepared with 2\%CA presented better rheological properties, however the swelling experiments showed obtaining of a poorer hydrogel from the point of view of $48 \mathrm{~h}$ stability in an aqueous media. After approximately 8 hours these hydrogels presented advances phenomena of degradation in the aqueous media used for investigations. This trend was explained as follows: with the increasing of polymers and CA concentrations, the phenomena of chains overlapping increases, favouring the cross-linking processes. For such systems, a higher viscosity decreases the mobility of polymeric chains, reducing possibility of macroradicals to react with each other in order to form chemical bonds. ${ }^{63}$ Considering the data obtained from sol-gel analysis and swelling capacity and confirmed by the rheology experiments, we believe that the hydrogel coded as 3_C-PVP_0.5\% CA presented the best properties. By assessing of rheological properties of $\mathrm{C}$ PVP hydrogels with $0.5 \% \mathrm{CA}$, we noticed a well-defined elastic behaviour $(G)$ depended on the absorbed dose. The magnitude of storage modulus $\left(G^{\prime}\right)$ ranged between $1800-8400 \mathrm{~Pa}$, and the best swelling properties in PBS at $37^{\circ} \mathrm{C}$ were found to be for those hydrogels cross-linked with radiation dose starting from 7.5 to $12.5 \mathrm{kGy}$. We can conclude that C-PVP hydrogels with different swelling and rheological properties can be formed via e-beam processing. The elastic moduli of human skin ranges between $500-1000 \mathrm{~Pa}^{64}$ and that of other tissues, brain, liver, fat, relaxed muscle or breast tissue ranges from $1000-10000 \mathrm{~Pa}^{65,66}$ In view of the above, the elastic modulus of C-PVP hydrogels matches that of human skin and soft tissue relevant to the successful application as wound dressings or tissue engineering of soft tissue. The unirradiated C-PVP system exhibits very low storage modulus within 4 to $25 \mathrm{~Pa}$ as function of the polymer concentration and radiation dose. Some studies reported obtaining of PVP-based hydrogels with a $G^{\prime}$ value ranging between 1000 Pa to 3000 Pa produced by UV and e-beam irradiation of aqueous solutions with different concentrations. ${ }^{61}$ Other studies related to UV-cross-linking of high concentration of PVP aqueous solution have shown formation of PVP hydrogels with a storage modulus $G^{\prime}=140 \mathrm{~Pa} .{ }^{67}$ The synthesis of C-PVP hydrogels without adding of CA via $\gamma$-radiation cross-linking reported by our group, revealed a storage modulus not higher than $88 \mathrm{~Pa}$ at the absorbed dose of $25 \mathrm{kGy} .^{40}$ Considering the above, the fabrication of "strong" C-PVP hydrogels with constant elastic properties $\left(G^{\prime}=1800\right.$ $8000 \mathrm{~Pa}$ ), able to absorbs large quantity of aqueous fluids similarly with physiological liquids can be performed via e-beam cross-linking in the absence of oxygen and throughout the addition of a small quantity of water soluble CA.

\subsection{Determination of crosslink density}

The critical parameters necessary to fully understand the network structure of a cross-linked hydrogel are: the cross-link density $\left(V_{e}\right)$, the average molecular weight between cross-links $\left(M_{C}\right)$, and the average distance between cross-links or mesh size $(\xi) .{ }^{68}$ The cross-link density $\left(V_{e}\right)$ is a parameter that describes the number of cross-linking points formed between different polymeric chains (inter-molecular cross-linking) or inside of the same polymeric chain (intra-molecular cross-linking) upon irradiation. This parameter is in direct relation with the radiation aborbed dose. The experimental values of $M_{C}, V_{e}$, and mesh size $(\xi)$ are summarized in Tables 3 and 4 . The C-PVP hydro- 
gels processed without adding CA presented higher values of $M_{C}$, by comparison with those hydrogels obtained with high concentration of CA. The magnitude of $M_{C}$ was depended on the absorbed dose, therefore large $M_{C}$, as well as large mesh sizes ( $\xi$ ) were attributed to a low densely hydrogel structure. Each hydrogel composition revealed independent behaviour as function of absorbed dose. The C-PVP hydrogels (1_C-PVP, respectively 3_C-PVP) irradiated at $40 \mathrm{kGy}$ showed a very large $M_{C}$, in contrast with hydrogels coded as 2_C-PVP. The investigated network parameters for C-PVP hydrogels produced in the presence of CA showed a reduced $M_{C}$, correlated with strong storage modulus $(G)$. The C-PVP hydrogels prepared by addition of $2 \% \mathrm{CA}$, showed a decrease of $M_{C}$ and $\xi$ up to $12.5 \mathrm{kGy}$, were above this dose, the average molecular weight between cross-links became larger. With decreasing of CA concentration, it seems that C-PVP systems can be cross-liked via e-beam irradiation with moderate radiation dose, close to the legal accepted sterilization dose ( $25 \mathrm{kGy}$ ) in order to obtain the best swelling and optimum rheological properties. As the number of cross-linking points and the magnitude of storage modulus $\left(G^{\prime}\right)$ is increased correlated with reduced values of $M_{C}$ and mesh size a densely packed hydrogel structure is evident. Thus, in order to produce a superabsorbent hydrogel of C-PVP with a demonstrated stability in PBS at $37{ }^{\circ} \mathrm{C}$ for at least $48 \mathrm{~h}$ and a degree of swelling above $1000 \%$, the average molecular weight between cross-links $\left(M_{C}\right)$ can range between 60 to $66 \mathrm{~kg} \mathrm{~mol}^{-1}$. The corresponding mesh size ( $\left.\xi\right)$ was found to be 53 to $54 \mathrm{~nm}$. The above mentioned parameters were determined on the basis of experimental values of storage modulus $(G)$ comprised between 2500-2800 Pa. The results obtained here indicate that the network parameters of the hydrogel coded as 3_C-PVP_CA $0.5 \%$ can be controlled by changing the absorbed dose.

\subsection{Fourier transform infrared spectra (FTIR)}

The FTIR spectra of the C-PVP hydrogels prepared without CA are shown in Figure 5. In order to evaluate the hydrogels composition, the FTIR spectra of the main hydrogels components were firstly analysed. The unirradiated (0 kGy) hydrogel (Figure 5(a)) showed a wide absorption band from 3700 to 2700 $\mathrm{cm}^{-1}$. In this region, peaks were identified at $3314 \mathrm{~cm}^{-1}$ (amide A), $3080 \mathrm{~cm}^{-1}$ (amide B), and $2921 \mathrm{~cm}^{-1}$ (stretching vibration of $\mathrm{C}-\mathrm{H}$ ). The peaks from $1645 \mathrm{~cm}^{-1}, 1550 \mathrm{~cm}^{-1}$, and $1235 \mathrm{~cm}^{-1}$ were attributed to collagen molecule and the peaks from $1423 \mathrm{~cm}^{-1}$ and $1288 \mathrm{~cm}^{-1}$ are specific of PVP. When the hydrogels were irradiated with $25 \mathrm{kGy}$, the intensity of the band between 3700 $2700 \mathrm{~cm}^{-1}$ increased and peaks were shifted towards low frequencies (amide A and B band). The intensity of amide B band decreased by an order of magnitude after irradiation with 40 $\mathrm{kGy}$, this might be associated with loss of collagen structural integrity. In the region $1700-600 \mathrm{~cm}^{-1}$ of FTIR spectra, the characteristic peaks have been preserved, however a decreasing in peaks intensity from $1550 \mathrm{~cm}^{-1}$ and $1235 \mathrm{~cm}^{-1}$ was also observed for the hydrogel prepared with $40 \mathrm{kGy}$. Moreover, the emergence of a new functional group was identified at $2852 \mathrm{~cm}^{-1}$ (CH stretching vibration) and at $1059 \mathrm{~cm}^{-1}$. The peak formed at $1059 \mathrm{~cm}^{-1}$ can be associated with the introduction of primary
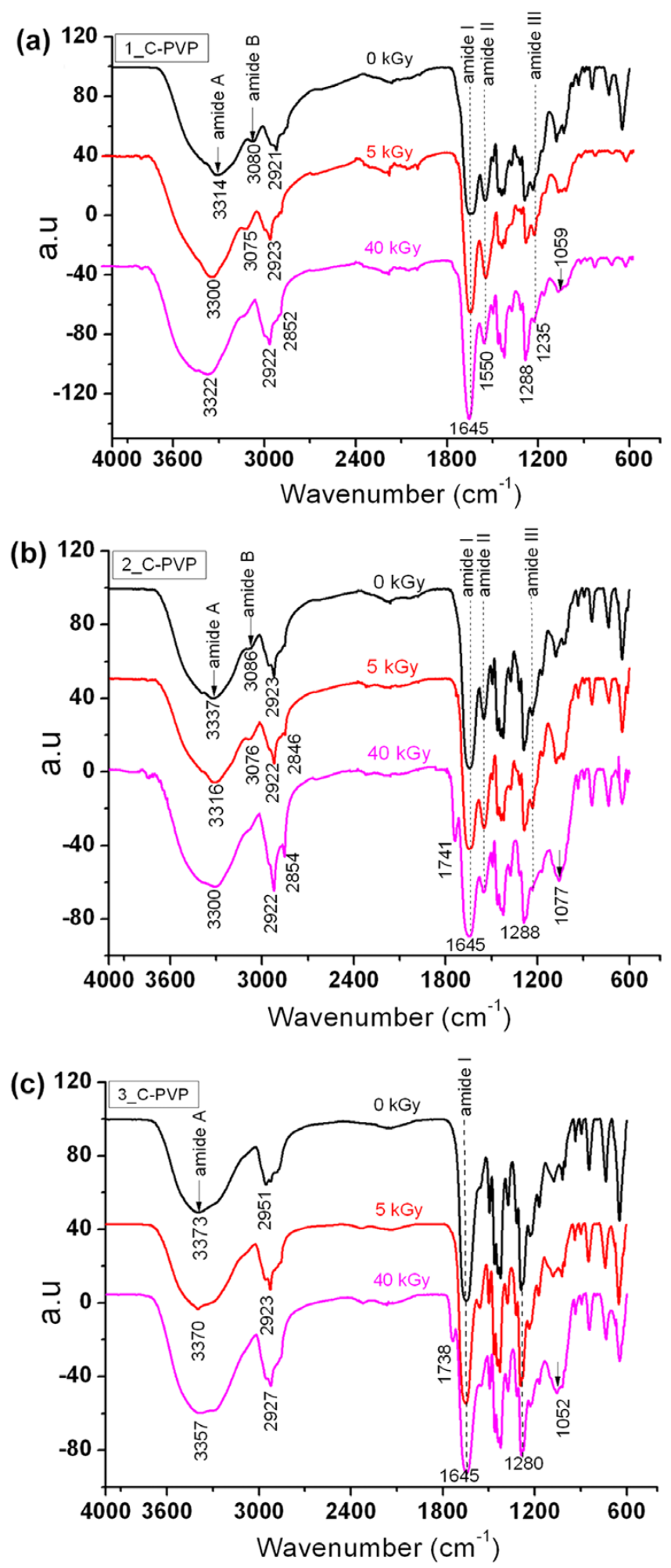

Figure 5. FTIR spectra of C-PVP hydrogels cross-linked via e-beam irradiation without CA.

alcohol groups probably as a result of oxidative phenomena after the exposure of the hydrogel at high radiation doses. ${ }^{61} \mathrm{In}$ the FTIR spectra of the hydrogel 2_C-PVP (Figure 5(b)), the main peaks were found at $3337 \mathrm{~cm}^{-1}, 3086 \mathrm{~cm}^{-1}, 2923 \mathrm{~cm}^{-1}, 1644 \mathrm{~cm}^{-1}$, $1550 \mathrm{~cm}^{-1}, 1283 \mathrm{~cm}^{-1}$, and $1083 \mathrm{~cm}^{-1}$. After e-beam irradiation with $5 \mathrm{kGy}$, the shifting of bands from $3337 \mathrm{~cm}^{-1}$ to $3316 \mathrm{~cm}^{-1}$, 
$3086 \mathrm{~cm}^{-1}$ to 3076 and formation of a new band at $2846 \mathrm{~cm}^{-1}$ was observed. Likewise, after irradiation with $40 \mathrm{kGy}$, the peaks were shifted towards lower wavelengths, from $3337 \mathrm{~cm}^{-1}$ to $3300 \mathrm{~cm}^{-1}$, followed by the increase of intensity at $2854 \mathrm{~cm}^{-1}$, and identification of new bands at $1741 \mathrm{~cm}^{-1}$ and at $1077 \mathrm{~cm}^{-1}$. The peak from $1741 \mathrm{~cm}^{-1}$ has been associated with $\mathrm{C}=0$ stretching vibrations, being specific to functional ketone groups belonging to a ring; this may be a consequence of scission of the macromolecular chains formed between collagen and PVP when the hydrogel is exposed to high radiation doses. Figure 5(c) shows the FTIR spectra of the hydrogel 3_C-PVP, with the characteristic peaks: $3373 \mathrm{~cm}^{-1}, 2951 \mathrm{~cm}^{-1}, 1645^{-1}, 1423 \mathrm{~cm}^{-1}, 1280 \mathrm{~cm}^{-1}$. After irradiation with $40 \mathrm{kGy}$ new peaks at $1738 \mathrm{~cm}^{-1}$ and $1052 \mathrm{~cm}^{-1}$ were identified, coupled with increasing of bands intensity in the region $3700-2700 \mathrm{~cm}^{-1}$. In FTIR spectra, the increasing of bands intensity is due to the introduction of new functional groups, mainly of $\mathrm{H}$-bond from $\mathrm{OH}$ groups, as well as due to the stretching vibration of $\mathrm{C}-\mathrm{H}, \mathrm{CH}_{2}$, and $\mathrm{CH}_{3}$ functional groups characteristic to aromatic molecules. The FTIR spectra of C-PVP hydrogels prepared with CA are shown in Figure 6. The spectra displayed broad absorption bands in the region $3700-2700 \mathrm{~cm}^{-1}$ with peaks at $3311-3315 \mathrm{~cm}^{-1}$, associated to the $\mathrm{OH}$ stretching vibrations originating from free and bound water, and free and coupled $\mathrm{NH}$ stretching vibrations. The broadening of absorption band is due to the AA and NMBA addition in the hydrogels composition and as their concentration is reduced, the characteristic peaks become narrower and more intense in the region 2900-2800 $\mathrm{cm}^{-1}$ (Figure 6(b) and (c)). The peaks from 2934-2936 $\mathrm{cm}^{-1}$ are related to the stretching vibrations of $\mathrm{CH}_{2}$, and those at 2853$2873 \mathrm{~cm}^{-1}$ correspond to $\mathrm{CH}$. In the range $1800-600 \mathrm{~cm}^{-1}$ the characteristic peaks corresponding to both collagen and PVP were found at: $1654 \mathrm{~cm}^{-1}$ and $1551 \mathrm{~cm}^{-1}$ (amide Iand amide II bands corresponding to collagen and PVP molecule), $1450 \mathrm{~cm}^{-1}, 1405$ $\mathrm{cm}^{-1}, 1292 \mathrm{~cm}^{-1}$. In Figure 6(b) the FTIR spectra of C-PVP hydrogels obtained by the addition of $1 \% \mathrm{CA}$ are displayed. The broad band characteristic to the amide A band was found at 3335$3350 \mathrm{~cm}^{-1}$.

The stretching vibrations corresponding to the $\mathrm{CH}_{2}$ and $\mathrm{CH}$ bonds were found between $2923-2926 \mathrm{~cm}^{-1}$, respectively at $2854 \mathrm{~cm}^{-1}$. The bands intensity attributed to the $\mathrm{CH}_{2}$ and $\mathrm{CH}$ functional groups has increased significantly for hydrogels cross-linked with $12.5 \mathrm{kGy}$. In the range $1800-600 \mathrm{~cm}^{-1}$, the characteristic peaks were preserved, except for the hydrogel irradiated with $40 \mathrm{kGy}$. For hydrogel cross-liked with doses higher than $25 \mathrm{kGy}$, it was observed the reduction of amide II band intensity coupled with the appearance of a shoulder located at $1720 \mathrm{~cm}^{-1}$, as well as the shifting of band from 1287 $\mathrm{cm}^{-1}$ to $1292 \mathrm{~cm}^{-1}$. The FTIR spectra of C-PVP hydrogels prepared with $0.5 \% \mathrm{CA}$ are shown in (Figure 6(c)). The amide II band intensity was preserved even the hydrogel was crosslinked with $40 \mathrm{kGy}$, no shoulder apparition was found. The amide I band was shifted to $1668 \mathrm{~cm}^{-1}$ (higher wavenumbers) and corresponding intensity was preserved as well. In the region $3700-2700 \mathrm{~cm}^{-1}$ the band intensity was decreased and the peak was shifted from $3300 \mathrm{~cm}^{-1}$ to $3360 \mathrm{~cm}^{-1}$, this can be associated with the chain scission of hydrogel network if the polymeric blend is exposed to higher dose than $25 \mathrm{kGy}$.
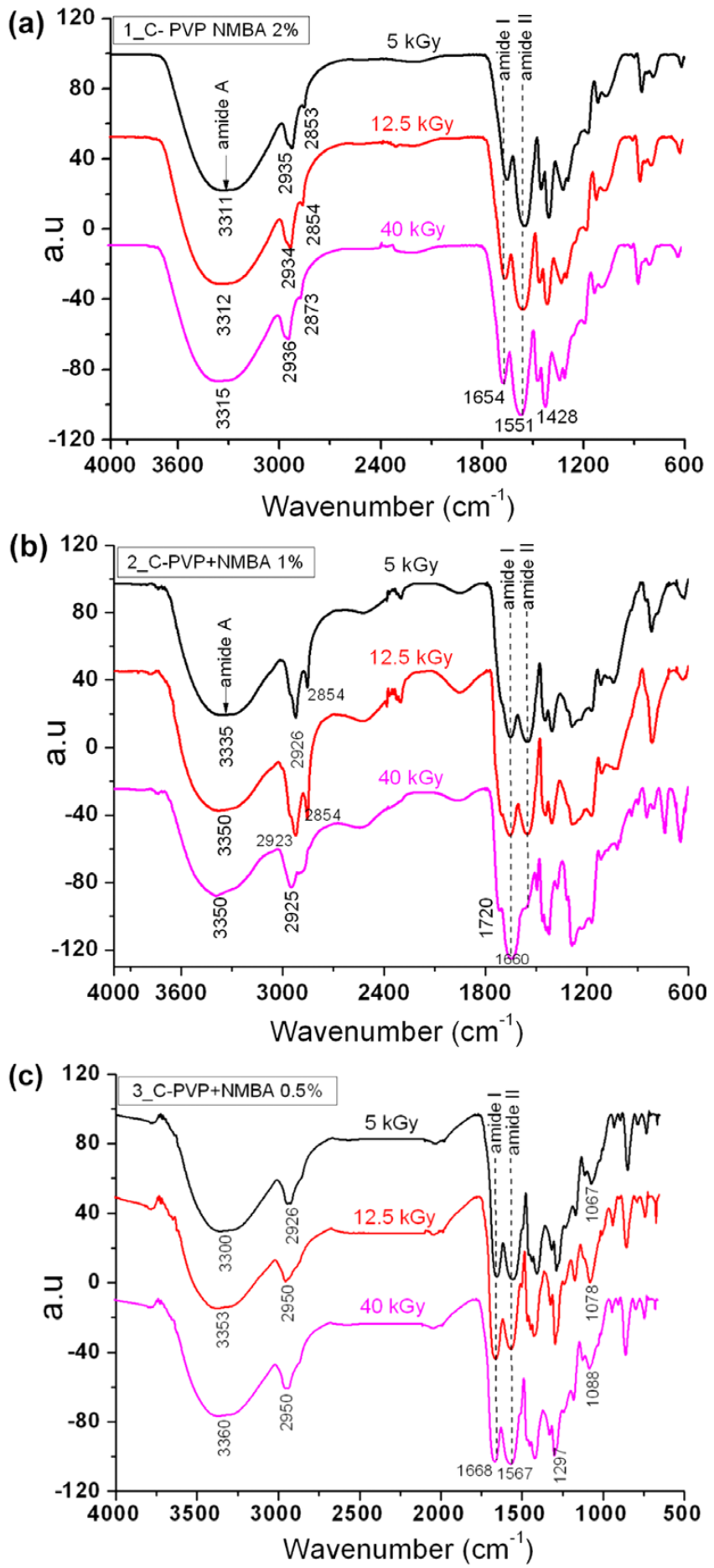

Figure 6. FTIR spectra of C-PVP hydrogels cross-linked via e-beam irradiation with CA.

\subsection{Scanning electron microscopy (SEM)}

Figure 7 presents the network morphologies of C-PVP hydrogels obtained with low concentration of $\mathrm{CA}(0.5 \%)$, equilibrated in phosphate buffer solution (PBS) at $37^{\circ} \mathrm{C}$, and cross-linked with radiation doses from $5 \mathrm{kGy}$ to $40 \mathrm{kGy}$.

The structure of the hydrogel varies with irradiation dose from a more compact form at lower irradiation dose to a more macroporous structure at high doses: a compact structure can be observed at $5 \mathrm{kGy}$ and $7.5 \mathrm{kGy}$ radiation doses, a loosely 

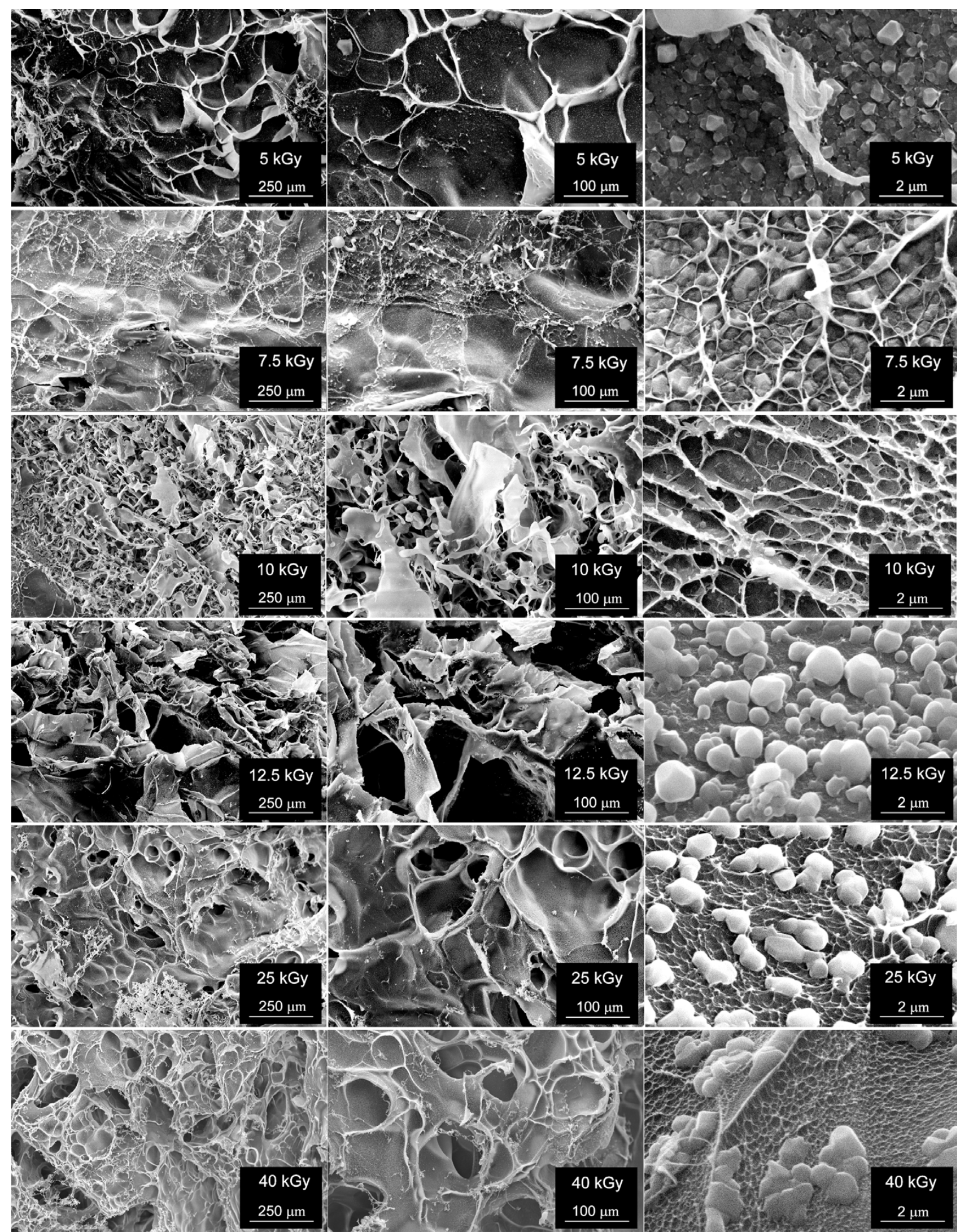

Figure 7. SEM images of C-PVP hydrogels cross-linked with absorbed dose within 5 kGy-40 kGy.

linked, large flake (approximately $50 \mu \mathrm{m}$ across), structure at the doses of $10 \mathrm{kGy}$ and $12.5 \mathrm{kGy}$ and at the final two irradiation doses, at $25 \mathrm{kGy}$ and $40 \mathrm{kGy}$, the structure has a macroporous state with large (approximately $50 \mu \mathrm{m}$ diameter) pores and strong matter bridges encircling the pores. At all irradiation doses, at high magnification, crystalline formations can be identified adhering to the macroporous surface of the hydrogel and also intertwined within the lattice structure. These crystal- 
line formations are thought to originate from the PBS that was used to swell the hydrogels.

\section{Conclusions}

Novel superabsorbent C-PVP hydrogels have been produced using e-beam processing as a principal promoter of the crosslinking reaction. The hydrogels were produced both in the presence and in the absence of cross-linking agents in order to achieve a comprehensive comparison between critical parameters of these types of materials. The C-PVP hydrogels prepared without addition of $\mathrm{CA}$, indicate a negligible contribution of chain scission processes in comparison with those hydrogels produced at high concentration of CA. The cross-linked network of C-PVP hydrogels exhibited excellent swelling capacity, both in deionized water, as well as in phosphate buffer solution (PBS, $37^{\circ} \mathrm{C}, \mathrm{pH}=7.4$ ). The hydrogels prepared without addition of $\mathrm{CA}$, reached the highest swelling degree about $3000 \%$, at the lowest absorbed dose. For all C-PVP hydrogels investigated here, the elastic modulus $(G)$ was constantly higher than the viscous modulus $\left(G^{\prime}\right)$, confirming that cross-linking reactions have prevailed during e-beam processing. Experimental data such as swelling ratio, the gel fraction (G\%) and elastic modulus, $G^{\prime}$, shows that the C-PVP hydrogels obtained throughout e-beam processing, present optimum values for the hydrogel with composition noted as 3_C-PVP prepared in the presence of $0.5 \%$ CA at the absorbed dose of 7.5-10-12.5 kGy. For those hydrogels prepared with high concentration of cross-linking agent, the chain scission processes have prevailed.

\section{References}

(1) V. Singh, Hydrogels: Applications and Global Markets to 2022, 1 (2017).

(2) A. Sood, M. S. Granick, and N. L. Tomaselli, Adv. Wound Care, 3, 511 (2014).

(3) Y. M. Lim, H. J. Gwon, J. S. Park, Y. C. Nho, J. W. Shim, I. K. Kwon, S. E. Kim, and S. H. Baik, Macromol. Res., 19, 436 (2011).

(4) N. E. Song, Y. R. Song, H. J. Gwon, Y. M. Lim, and S. H. Baik, Macromol. Res., 20, 1137 (2012).

(5) Haryanto, S. Kim, J. H. Kim, J. O. Kim, S. Ku, H. Cho, D. H. Han, and P. Huh, Macromol. Res., 22, 131 (2014).

(6) J. M. Rosiak and F. Yoshii, Nucl. Instr. Meth. Phys. Res. B, 151, 56 (1999).

(7) J. Rosiak, A. Rucinska-Rybus, and W. Pekala, Politechnika Lodzka, U.S. Patent 4871490 (1989).

(8) J. M. Rosiak and P. Ulanski, Radiat. Phys. Chem., 55, 139 (1999).

(9) S. Benamer, M. Mahlous, A. Boukrif, B. Mansouri, and S. L. Youcef, Nucl. Instr. Meth. Phys. Res. B, 248, 284 (2006).

(10) B. I. Da Silveira, Eur. Polym. J., 29, 1095 (1993).

(11) C. Dispenza, N. Grimaldi, M. A. Sabatino, S. Todaro, D. Bulone, D. Giacomazza, G. Przybytniak, S. Alessi, and G. Spadaro, Radiat. Phys. Chem., 81, 1349 (2012).

(12) H. Foroutan, M. Khodabakhsh, and M. Rabbani, Iran. J. Radiat. Res., 5, 131 (2007).

(13) Z. Aji, Nucl. Instr. Meth. Phys. Res. B, 265, 179 (2007).

(14) H. K. Can, Radiat. Phys..Chem., 72, 703 (2005).

(15) A. B. Lugao, L. D. B. Machado, L. F. Miranda, M. R. Alvarez, and J. M. Rosiak, Radiat. Phys. Chem., 52, 319 (1998).

(16) A. B. Lugao, S. O. Rogero, and S. M. Malmonge, Radiat. Phys. Chem., 63, 543 (2002).
(17) S. Oren, T. Caykara, O. Kantoglu, and O. Güven, J. Appl. Polym. Sci, 78, 2219 (2000).

(18) T. Caykara, S. Oren, O. Kantoglu, and O. Güven, J. Appl. Polym. Sci., 77, 1037 (2000).

(19) C. Ozyurek, T. Caykara, O. Kantoglu, and O. Güven, Polym. Adv. Technol., 13, 87 (2002).

(20) K. Sohail, I. U. Khan, Y. Shahzad, T. Hussain, and N. M. Ranjha, Braz. J. Pharm. Sci., 50, 173 (2014).

(21) S. G. A. Alla, H. M. N. El-Din, and A. W. M. El-Naggar, Eur. Polym. J., 43, 2987 (2007).

(22) A. E. H. Ali, H. A. Shawky, H. A. Abd el Rehim, and E. A. Hegazy, Eur. Polym. J., 39, 2337 (2003).

(23) S. Kadlubowski, A. Henke, P. Ulanski, and J. M. Rosiak, Radiat. Phys. Chem., 79, 261 (2010).

(24) H. A. A. El-Rehim, E. A. Hegazy, F. H. Khalil, and N. A. Hamed, Nucl. Instr. Meth. Phys. Res. B, 254, 105 (2007).

(25) M. B. Thurmer, C. E. Diehl, F. J. B. Brum, and L. A. dos Santos, Mater. Res.-Ibero-Am. J., 17, 109 (2014).

(26) S. P. Jin, M. Z. Liu, F. Zhang, S. L. Chen, and A. Z. Niu, Polymer, 47, 1526 (2006).

(27) S. Jin, J. Gu, Y. Shi, K. Shao, X. Yu, and G. Yue, Eur. Polym. J., 49, 1871 (2013).

(28) H. Jang, H. Choi, H. Jeong, S. Baek, S. Han, D. J. Chung, and H. S. Lee, Macromol. Res., 26, 151 (2018).

(29) N. Inoue, M. Bessho, M. Furuta, T. Kojima, S. Okuda, and M. Hara, J. Biomater. Sci. Polym. Ed., 17, 837 (2006).

(30) J. C. Yu, S. K. Yeo, T. H. Kim, D. S. Shu, and C. H. Chang, Sewon Cellontech Co., C.A. Patent 2823686 (2012).

(31) B. Jiang, Z. H. Wu, H. C. Zhao, F. Y. Tang, J. Lu, Q. R. Wei, and X. D. Zhang, Biomaterials, 27, 15 (2006).

(32) B. Jiang, Y. Zhou, Z. Yang, Z. H. Wu, G. L. Huang, L. B. Lin, and X. D. Zhang, J. Appl. Polym. Sci., 98, 2094 (2005).

(33) F. Cataldo, O. Ursini, E. Lilla, and G. Angelini, J. Radioanal. Nucl. Chem., 275, 125 (2008).

(34) X. M. Zhang, L. Xu, X. Huang, S. C. Wei, and M. L. Zhai, J. Biomed. Mater. Res. B, 100A, 2960 (2012).

(35) A. Sionkowska, Eur. Polym. J., 39, 2135 (2003).

(36) A. Sionkowska, H. Kaczmarek, M. Wisniewski, J. Kowalonek, and J. Skopinska, Surf. Sci., 566, 608 (2004).

(37) A. Sionkowska, M. Wisniewski, H. Kaczmarek, J. Skopinska, P. Chevallier, D. Mantovani, S. Lazare, and V. Tokarev, Appl. Surf. Sci, 253, 1970 (2006).

(38) G. Leyva-Gomez, E. Lima, G. Krotzsch, R. Pacheco-Marin, N. Rodriguez-Fuentes, D. Quintanar-Guerrero, and E. Krotzsch, J. Phys. Chem. $B, 118,9272$ (2014).

(39) M. Gonzalez-Torres, G. Leyva-Gomez, M. Rivera, E. Krotzsch, R. Rodriguez-Talavera, A. L. Rivera, and A. Cabrera-Wrooman, Mater. Lett, 214, 224 (2018).

(40) M. Demeter, M. Virgolici, C. Vancea, A. Scarisoreanu, M. G. A. Kaya, and V. Meltzer, Radiat. Phys. Chem., 131, 51 (2017).

(41) M. Dumitraşcu, V. Meltzer, E. Sima, M. Vîrgolici, M.G. Albu, A. Ficai, V. Moise, R. Minea, C. Vancea, A. Scarisoreanu, and F. Scarlat, Dig. J. Nanomater. Biostruct, 6, 1793 (2011).

(42) D. S. Jones, Int. J. Pharm., 179, 167 (1999).

(43) N. E. Ben Ammar, T. Saied, M. Barbouche, F. Hosni, A. H. Hamzaoui, and M. Şen, Polym. Bull., 75, 3825 (2018).

(44) V. Trandafir, G. Popescu, G. M. Albu, H. Iovu, and M. Georgescu, Bioproduse pe baza de colagen, Universitatea din București - Editura, "Ars Docendi", Bucharest, 2007.

(45) ISO/ASTM51631, Practice for use of calorimetric dosimetry systems for electron beam dose measurements and dosimetery system calibrations (2013).

(46) J. Olejniczak, J. Rosiak, and A. Charlesby, Int. J. Radiat. Appl. Instrum., 
Part C, 38, 113 (1991).

(47) A. Charlesby, Radiat. Phys. Chem., 37, 5 (1991).

(48) L. R. G. Treloar, The Physics of Rubber Elasticity, Oxford University Press Inc., New York, 2005.

(49) J. E. Mark and B. Erman, Rubberlike Elasticity, Cambridge University Press, New York, 2007.

(50) A. Cao, Y. L. Tang, Y. Liu, H. X. Yuan, and L. B. Liu, Chem.Commun., 49, 5574 (2013).

(51) T. Su, D. Zhang, Z. Tang, Q. Wu, and Q. G. Wang, Chem. Commun., 49, 8033 (2013).

(52) J. M. Rosiak, I. Janik, S. Kadlubowski, M. Kozicki, P. Kujawa, P. Stasica, and P. Ulanski, in Radiation synthesis and modification of polymers for biomedical applications, IAEA-TECDOC-1324, Vienna, 2002.

(53) W. Mozalewska, R. Czechowska-Biskup, A. K. Olejnik, R. A. Wach, P. Ulanski, and J. M. Rosiak, Radiat. Phys. Chem., 134, 1 (2017).

(54) M. Şen, H. Hayrabolulu, P. Taşkın, M. Torun, M. Demeter, M. Cutrubinis, and O. Güven, Radiat. Phys. Chem., 124, 225 (2016).

(55) H. Hayrabolulu, M. Demeter, M. Cutrubinis, O. Güven, and M. Şen, Radiat. Phys. Chem., 144, 189 (2018).

(56) N. V. Gupta and H. G. Shivakumar, Iran J. Pharm. Res., 11, 481 (2012).

(57) N. Roy, N. Saha, T. Kitano, P. S. Roy, N. Saha, and P. S. Takeshi Kitano, J.
Appl. Polym. Sci., 117, 1703 (2010).

(58) T. Mezger, The Rheology Handbook: For Users of Rotational and Oscillatory Rheometers, Vincentz Network, Hannover, 2002.

(59) K. S. Anseth, C. N. Bowman, and L. Brannon Peppas, Biomaterials, 17, 1647 (1996).

(60) M. Ricca, V. Fodera, D. Giacomazza, M. Leone, G. Spadaro, and C. Dispenza, Colloid Polym. Sci., 288, 969 (2010).

(61) C. Dispenza, M. Ricca, C. LoPresti, G. Battaglia, M. La Valle, D. Giacomazza, and D. Bulone, Polym. Chem., 2, 192 (2011).

(62) L. Zhao, H. Mitomo, and F. Yoshii, J. Bioact. Compat. Polym., 23, 319 (2008).

(63) A. Chapiro and C. Legris, Radiat.Phys. Chem., 28, 143 (1986).

(64) B. Holt, A. Tripathi, and J. Morgan, J. Biomech., 41, 2689 (2008).

(65) C. M. Nimmo, S. C. Owen, and M. S. Shoichet, Biomacromolecules, 12, 824 (2011).

(66) D. E. Discher, D. J. Mooney, and P. W. Zandstra, Science, 324, 1673 (2009).

(67) G. D'Erricot, M. De Lellis, G. Mangiapia, A. Tedeschi, O. Ortona, S. Fusco, A. Borzacchiello, and L. Ambrosio, Biomacromolecules, 9, 231 (2008).

(68) N. A. Peppas, Y. Huang, M. Torres-Lugo, J. H. Ward, and J.Zhang, Annu. Rev. Biomed. Eng., 2, 9 (2000). 